\title{
Radiosensitization of human breast cancer cells to ultraviolet light by 5-fluorouracil
}

\author{
KAZUHITO SASAKI ${ }^{1}$, NELSON H. TSUNO ${ }^{1,2}$, EIJI SUNAMI ${ }^{1}$, KAZUSHIGE KAWAI ${ }^{1}$, YASUTAKA SHUNO ${ }^{1}$, \\ KUMIKO HONGO $^{1}$, MASAYA HIYOSHI ${ }^{1}$, MANABU KANEKO ${ }^{1}$, KOJI MURONO ${ }^{1}$, NORIKO TADA ${ }^{1}$, \\ TAKAKO NIREI $^{1}$, JOJI KITAYAMA ${ }^{1}$, KOKI TAKAHASHI ${ }^{2}$ and HIROKAZU NAGAWA ${ }^{1}$
}

Departments of ${ }^{1}$ Surgical Oncology and ${ }^{2}$ Transfusion Medicine, Faculty of Medical Sciences, The University of Tokyo, Tokyo, Japan

Received November 18, 2010; Accepted February 22, 2011

DOI: $10.3892 / 01.2011 .261$

\begin{abstract}
Ultraviolet light B (UVB) phototherapy is widely used to treat dermatological diseases and therefore may be a potential optional strategy in the treatment of a skin lesion infiltrated by a malignant tumor. Currently, little is known regarding the effect of UVB phototherapy on human breast cancer cells. The present study aimed to investigate the effect of UVB phototherapy, as well as the potential effect of 5-fluorouracil (5-FU), the first-line anticancer drug for breast cancer, on radiosensitizing MCF-7 human breast cancer cells, in an attempt to develop new therapeutic strategies for the treatment of locoregional recurrence of breast cancer. MCF-7 cells were incubated in the presence of 5-FU for $48 \mathrm{~h}$, and UVB irradiation at $750 \mathrm{~mJ} / \mathrm{cm}^{2}$ was administered in the midterm of 5-FU treatment. The viability of MCF-7 cells was analyzed by the trypan blue staining method. Apoptosis was quantified by flow cytometry and Hoechst 33258 staining. The cell cycle was evaluated by flow cytometry after the staining of cells with propidium iodide. The combination treatment of 5-FU and UVB resulted in a strong potentiation of the inhibitory effect of MCF-7 cell growth, dependent on the intra-S phase cell cycle arrest and induction of apoptosis, when compared to treatment with 5-FU or UVB alone. In conclusion, 5-FU sensitized human breast cancer cells to UVB phototherapy, and this combination therapy is an effective and promising strategy for the treatment of breast cancer, particularly for locoregional recurrence.
\end{abstract}

\section{Introduction}

Phototherapy using ultraviolet light B (UVB, range 290-320 nm) has widespread therapeutic applications for the treatment of dermatological diseases. Narrow-band UVB

Correspondence to: Dr Kazuhito Sasaki, The University of Tokyo, 7-3-1 Hongo, Bunkyo-ku, Tokyo 113-8655, Japan

E-mail: sasakik-sur@h.u-tokyo.ac.jp

Key words: ultraviolet light B, 5-fluorouracil, human breast cancer cells
(NB-UVB), which emits a concentrated UVB source of $311 \mathrm{~nm}$, has been shown to have a more profound therapeutic efficacy for the treatment of psoriasis, pruritus, cutaneous T-cell lymphoma and vitiligo (1-5). Moreover, it has been shown that NB-UVB is as effective as psoralen in combination with ultraviolet A (PUVA) for psoriasis without systemic toxicity (6). In normal human cells, UVB induces inflammation and DNA damage (7). During mild exposure to UVB, DNA repair systems are activated (8). However, prolonged exposure to UVB results in irreparable DNA damage, and programmed cell death, such as apoptosis (9), results. Thus, the mechanism of action of UVB in the clinical settings of dermatological disease treatment is dependent on the induction of apoptosis (10).

On the other hand, as regards cancer treatment, the standard treatment modality for the majority of malignant tumors includes surgical resection combined with radiotherapy and chemotherapy, and 5-fluorouracil (5-FU) is a widely used anticancer agent. Intracellular metabolites of 5-FU can exert cytotoxic effects via inhibition of thymidylate synthetase, or through incorporation into RNA and DNA, events that ultimately activate apoptosis and cell cycle arrest (11). It is frequently used in combination with radiotherapy, which is anticipated to improve cancer treatment. Chemotherapy is reported to radiosensitize various types of tumors, and may improve the outcome of cancer radiotherapy $(12,13)$. Multiple mechanisms appear to be involved in the radiosensitization of tumor cells by chemotherapy, such as the potentiation of radiation damage (base damage, DNA single- and doublestrand breaks), the inhibition of post-irradiation DNA repair, the redistribution of the cell cycle, and the augmentation of apoptosis $(14,15)$.

Locoregional recurrence of breast cancer is reported to occur in $10-13 \%$ of patients within 10 years of breast conservation therapy and also in 3-8\% of those who received mastectomy and postoperative radiotherapy $(16,17)$. The general management for chest wall recurrences of breast cancer, as well as other types of cancer, is structured on the extent and volume of local disease, the absence of distant metastasis, general health of the patient, and the extent of prior local therapies, particularly radiation (18). Surgical resection is indicated for those patients with isolated chest wall recurrence 
following mastectomy. In case of unresectable disease, neoadjuvant chemotherapy is considered, in order to render the disease resectable. Postoperative radiotherapy involving the chest wall and regional lymph nodes is recommended for those patients with isolated chest wall recurrence, without a history of prior radiotherapy. In case of patients with a history of previous irradiation, the design of radiation fields and the radiation doses are restricted by prior therapies (18). Occasionally, the cancer pain and pruritus that occurs when skin is affected by a malignant tumor can be intractable. Thus, cancer pain and pruritus are considered difficult therapeutic issues (19). In the situation that radiotherapy is not applicable due to prior therapies, UVB phototherapy may be a potential optional strategy to treat a skin lesion infiltrated by a malignant tumor.

Presently, little is known regarding the effect of UVB phototherapy on human breast cancer cells. Thus, in the present study we aimed to investigate the effect of UVB phototherapy, as well as the potential effect of 5-FU, the firstline anticancer drug for breast cancer, on radiosensitizing MCF-7 human breast cancer cells, in an attempt to develop new therapeutic strategies for the treatment of locoregional recurrence of breast cancer.

\section{Materials and methods}

Cell cultures and UV-irradiation. The human breast cancer cell line, MCF-7, obtained from the Riken Cell Bank (Tsukuba, Japan), was cultured in RPMI-1640 supplemented with $5 \%$ fetal calf serum and $1 \%$ antibiotics/antimycotics (complete medium), and then incubated in a $5 \% \mathrm{CO}_{2}$ incubator at $37^{\circ} \mathrm{C}$. Bovine serum albumin, RPMI-1640 and 5-FU were purchased from Sigma-Aldrich (St. Louis, MO, USA). Fetal calf serum and antibiotics/antimycotics were from Gibco-BRL (Grand Island, NY, USA). Cells were plated at $2 \times 10^{5}$ cells/well into 6 -well plates and at $5 \times 10^{6}$ into $100-\mathrm{mm}$ dishes and were placed in an incubator. To assess the effects of the co-treatment with UVB and 5-FU, cells were grown to $50 \%$ confluence and treated without or with 5-FU (10 and $20 \mu \mathrm{M}$ doses) for $48 \mathrm{~h}$. UVB-irradiation was administered in the midterm during the 48-h 5-FU treatment period. MCF-7 cells were irradiated with UVB at $750 \mathrm{~mJ} / \mathrm{cm}^{2}$ with the use of DNA-FIX apparatus (UV lamp at $312 \mathrm{~nm}$, Atto Co., Tokyo, Japan) at room temperature (20). Exposure time was $3 \mathrm{~min}\left(750 \mathrm{~mJ} / \mathrm{cm}^{2}\right)$, and no heat was detectable during UV-irradiation.

Cell viability assessment. Cells were treated as described, and cell growth was assessed by counting viable cells following trypan blue staining. Experiments were performed in triplicate wells, and the viability of MCF-7 cells was calculated as the ratio of each experimental condition to the control condition (untreated cells). The ratio of cell viability was expressed as mean $\pm \mathrm{SD}$.

Detection of apoptosis by flow cytometry and fluorescence microscopy. Cells were treated as described and then stained with fluorescein isothiocyanate (FITC)-conjugated Annexin V and propidium iodide (PI) for $5 \mathrm{~min}$ at room temperature according to the manufacturer's instructions (Annexin V-FITC Apoptosis Detection kit, BD Pharmingen, San Jose, CA, USA).
The population of Annexin V-PI- viable cells and Annexin $\mathrm{V}^{+} \mathrm{PI}^{+}$and Annexin $\mathrm{V}^{+} / \mathrm{PI}^{-}$apoptotic cells was evaluated by flow cytometry, and both Annexin $\mathrm{V}^{+}$cell populations were considered to be apoptotic cells. Data were collected in a FACSCalibur (Becton-Dickinson, Mountain View, CA, USA) and analyzed using CellQuest software (Becton-Dickinson). The experiment was performed three times, and the ratio of apoptotic cells was expressed as mean \pm SD.

To confirm the induction of apoptosis MCF-7 cells fixed with $4 \%$ paraformaldehyde were stained with $2 \mu \mathrm{g} / \mathrm{ml}$ Hoechst 33258, a fluorescent DNA binding dye, for $30 \mathrm{~min}$. Fluorescence of Hoechst 33258 was captured with a chargecoupled device camera under a fluorescent microscope. Apoptotic cells were identified by their typical morphological appearance, including chromatin condensation and nuclear fragmentation (21). An average of 200 nuclei from random fields was analyzed for each data point. The experiment was performed three times, and the ratio of apoptotic cells was expressed as mean $\pm \mathrm{SD}$.

Analysis of the cell cycle by flow cytometry. MCF-7 cells were prepared and treated as described. The percentage of cells in each phase of the cell cycle was analyzed by flow cytometry, using the Cycle Test Plus DNA Reagent kit (BD Pharmingen) according to the manufacturer's instructions, which is based on the measurement of the DNA content of nuclei labeled with PI. Treated cells were trypsinized (250 $\mu 1$ of trypsin buffer) for $10 \mathrm{~min}$ at room temperature, and then trypsin inhibitor (200 $\mu \mathrm{l})$ and RNase buffer were added and allowed to react for $10 \mathrm{~min}$ at room temperature. Finally, PI stain solution $(200 \mu \mathrm{l})$ was added and cells were incubated for $10 \mathrm{~min}$ in the dark on ice. Samples were immediately analyzed in a flow cytometer (Becton-Dickinson) and the results obtained were analyzed by CellQuest software. The experiment was performed three times, and the ratio of cells in the G1, intra-S and $\mathrm{G} 2 / \mathrm{M}$ phases was expressed as mean $\pm \mathrm{SD}$.

Statistical analysis. The results were expressed as mean \pm SD. Statistical analysis of all data between the control and treated groups was performed by analysis of variance. $\mathrm{P}<0.05$ was considered to be statistically significant.

\section{Results}

Effect of 5-FU on UVB-induced inhibition of cell viability of MCF-7 cells. Treatment with UVB alone resulted in inhibition of the viability of MCF-7 cells to approximately $74 \%$ of the untreated control cells. Treatment with 5-FU alone at 10 and $20 \mu \mathrm{M}$ resulted in inhibition of the viability of MCF-7 cells to approximately 82 and $63 \%$, respectively, of the untreated control cells. The combination treatment of 5-FU and UVB resulted in a strong potentiation of the inhibitory effect (74 vs. 29 and $19 \%$ viable cells for UVB alone vs. UVB + 5-FU at 10 and $20 \mu \mathrm{M}$, respectively) (Fig. 1).

5-FU potentiated UVB-induced apoptosis in MCF-7 cells. Treatment of cells with 5-FU alone resulted in a slight increase in apoptotic cells (12.2 vs. 15.2 and 17.2\%; untreated vs. 5-FU at 10 and $20 \mu \mathrm{M})$. UVB-therapy alone also induced apoptosis in MCF-7 cells (12.2 vs. 39.8\%; untreated vs. UVB 


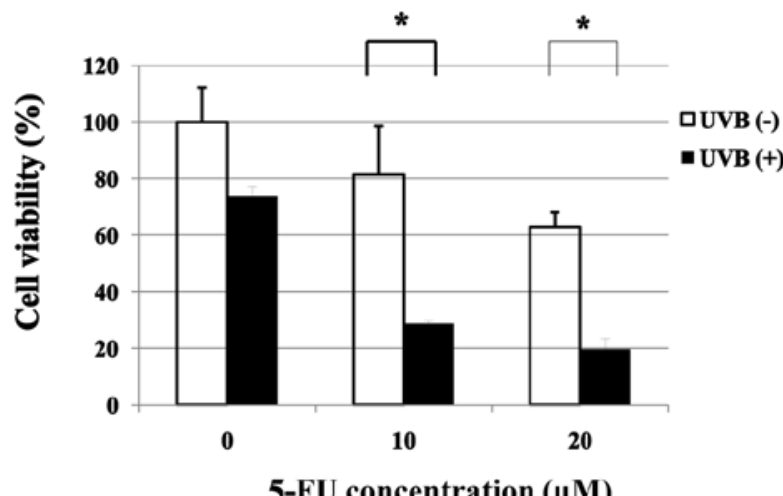

Figure 1. 5-Fluorouracil (5-FU) potentiated the inhibitory effect of UVB on the proliferative ability (viability) of MCF-7 cells. MCF-7 cells were incubated in the absence or presence of 5-FU $(10$ or $20 \mu \mathrm{M})$ without or with UVB-irradiation $\left(750 \mathrm{~mJ} / \mathrm{cm}^{2}\right)$, administered in the midterm of 5 -FU treatment, and the proliferative ability (viability) was evaluated by trypan blue exclusion staining. The $y$-axis shows the cell viability rate, calculated as the ratio of MCF-7 cells to control untreated cells. Co-treatment of cells with 5-FU and UVB-irradiation $\left(750 \mathrm{~mJ} / \mathrm{cm}^{2}\right)$ resulted in the potentiation of the inhibitory effect (74 vs. 29 and 19\% viable cells for UVB alone vs. $\mathrm{UVB}+5-\mathrm{FU}$ at 10 and $20 \mu \mathrm{M}$, respectively). The experiment was performed three times, and the inhibition (viability) rate was expressed as mean $\pm \mathrm{SD}$. ${ }^{*} \mathrm{P}<0.05$.

alone). When the cells were treated with the combination of 5-FU and UVB, a significant increase in the percentage of apoptotic cells was observed (39.8 vs. 62.2 and $74.1 \%$; UVB alone vs. UVB + 5-FU at 10 and $20 \mu \mathrm{M}$ ) (Fig. 2).

The induction of apoptosis was also confirmed by Hoechst 33258 staining. UVB-treated cells exhibited highly condensed and fragmented nuclei morphology, which are the typical features of apoptosis (1.3 vs. 26.0\%; untreated vs. UVB alone). 5-FU treatment strongly enhanced UVB-induced apoptosis in MCF-7 cells (26.0 vs. 34.3 and 50.6\%; UVB alone vs. UVB + 5-FU at 10 and $20 \mu \mathrm{M}$ ) (Fig. 3).

5-FU potentiated the arrest of MCF-7 cells treated with UVB in the intra-S phase of the cell cycle. Treatment of MCF-7 cells with 5-FU alone for $24 \mathrm{~h}$ resulted in a significant intra-S cell cycle arrest (percentage of cells in S phase: $27.3 \pm 3.9$ vs. $46.6 \pm 0.6$ and $42.7 \pm 4.5 \%$; untreated vs. $5-\mathrm{FU}$ at 10 and $20 \mu \mathrm{M}$ ), which became less evident after $48 \mathrm{~h}$ of treatment with 5 -FU alone (percentage of cells in $\mathrm{S}$ phase: $23.6 \pm 0.2$ vs. $26.0 \pm 0.7$,

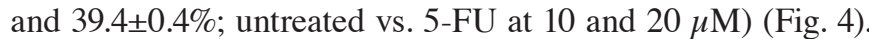
Concomitant with intra-S phase arrest, a significant decrease was noted in both $\mathrm{G} 1$ and G2/M phases. In contrast, treatment of MCF-7 cells with UVB alone resulted in cell cycle arrest in the G1 phase. In combination with 5-FU, compared with cells treated with UVB alone, an increase was noted in the percentage of cells in the intra-S phase, (percentage of cells in $S$ phase: $24.2 \pm 0.4$ vs. $36.4 \pm 0.6$ and $36.0 \pm 0.6 \%$ for UVB alone vs. UVB +5 -FU at 10 and $20 \mu \mathrm{M}$, respectively). When compared with cells treated with 5-FU alone at $10 \mu \mathrm{M}$ for $48 \mathrm{~h}$, a significant increase was noted in cells in the intra-S phase with a concomitant decrease in cells in the G2/M phase [percentage of cells in $\mathrm{S}$ phase and G2/M phase: $26.0 \pm 0.7$ vs. $36.4 \pm 0.6$ and $24.6 \pm 0.6 \%$ vs. $11.2 \pm 0.8 \%$ for $5-\mathrm{FU}$ alone $(10 \mu \mathrm{M})$ vs. UVB + 5-FU (10 $\mu \mathrm{M})$, respectively] (Fig. 4).

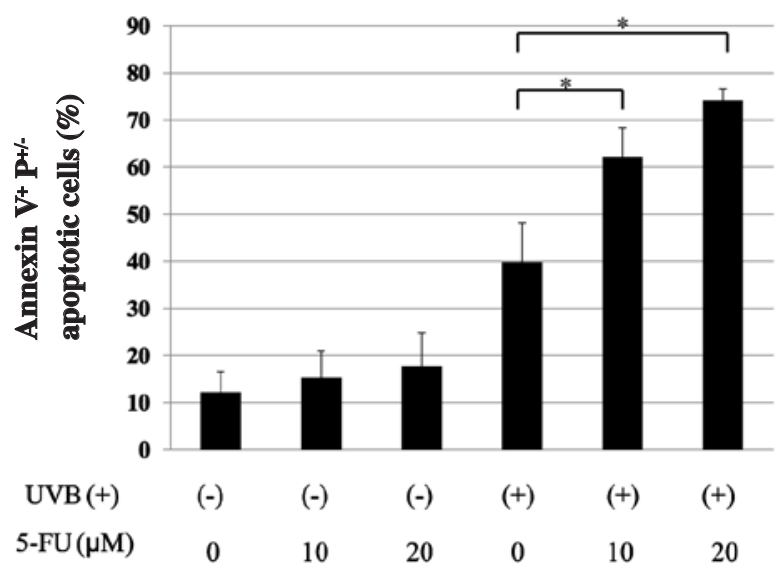

Figure 2. UVB-induced apoptosis of MCF-7 cells detected by flow cytometry was potentiated by 5-fluorouracil (5-FU). The population of Annexin $\mathrm{V}^{+} \mathrm{PI}^{+/}$ apoptotic cells was evaluated by flow cytometry using Annexin V-FITC/PI staining in MCF-7 cells, treated in the absence or presence of 5-FU (10 or $20 \mu \mathrm{M})$ without or with UVB-irradiation $\left(750 \mathrm{~mJ} / \mathrm{cm}^{2}\right)$. Treatment with 5-FU alone caused a slight increase in the percentage of apoptotic cells (12.2 vs. 15.2 and $17.2 \%$; untreated vs. treated with 5-FU at 10 and $20 \mu \mathrm{M})$. UVB-irradiation alone also caused a partial increase in apoptotic cells (12.2 vs. 39.8\%; untreated vs. UVB alone), while the combination treatment of 5-FU and UVB resulted in a significant increase in apoptotic cells (39.8 vs. 62.2 and $74.1 \%$; UVB alone vs. UVB +5 -FU at 10 and $20 \mu \mathrm{M})$. The experiment was performed three times, and the ratio of apoptotic cells was expressed as mean $\pm \mathrm{SD}$. ${ }^{*} \mathrm{P}<0.05$.

\section{Discussion}

Phototherapy has emerged as a promising therapeutic tool for the treatment of dermatologic conditions such as psoriasis, pruritus, cutaneous T-cell lymphoma, superficial basal cell carcinoma and malignant melanoma $(1,2,5,22,23)$. Phototherapy requires the simultaneous presence of photosensitizers, which accumulate in target cells resulting in the induction of apoptosis or necrosis. A variety of anti-cancer drugs, such as 5-FU, cisplatin and taxol, have been accepted as clinically useful radiosensitizers (24-26). Therefore, we hypothesized that 5 -FU is a potential radiosensitizer in potentiating the anti-cancer effect of UVB phototherapy in breast cancer cells.

In preliminary experiments, we tested the effect of UVB-irradiation on MCF-7 human breast cancer cells and observed that UVB at a dose of 500,750 and $1000 \mathrm{~mJ} / \mathrm{cm}^{2}$ had an aproximately $15-30 \%$ inhibitory effect in the cell viability assay. The doses of UVB are used in the clinical treatment of cutaneous T-cell lymphoma (5), and the dose of $750 \mathrm{~mJ} /$ $\mathrm{cm}^{2}$, which had minimal inhibitory effect on cell viability, was selected for subsequent experiments. In constrast, treatment of MCF-7 with 5-FU alone at concentrations of 10 and $20 \mu \mathrm{M}$ for $48 \mathrm{~h}$ resulted in 18 and $37 \%$ inhibition of the proliferative activity of MCF-7 cells, respectively. In addition, the combination of 5-FU (10 and $20 \mu \mathrm{M})$ and UVB $(750 \mathrm{~mJ} /$ $\mathrm{cm}^{2}$ ) significantly potentiated an inhibitory effect on MCF-7 cell growth. Consequently, 5-FU at 10 and $20 \mu \mathrm{M}$ for $48 \mathrm{~h}$ and UVB-irradiation at $750 \mathrm{~mJ} / \mathrm{cm}^{2}$ in the midterm of 5 -FU treatment were selected for subsequent experiments.

UVB alone inhibited the viability of MCF-7 cells by approximately $26 \%$ and was dependent on the induction of apoptosis and cell cycle arrest in the G1 phase. As indicated 
5-FU

0

A UVB

$(-)$

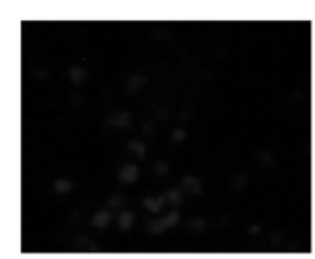

(+)

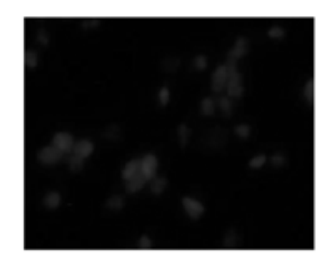

20
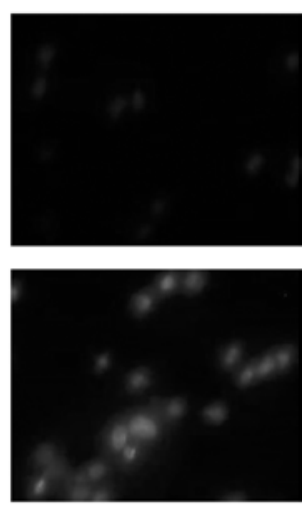

*

B

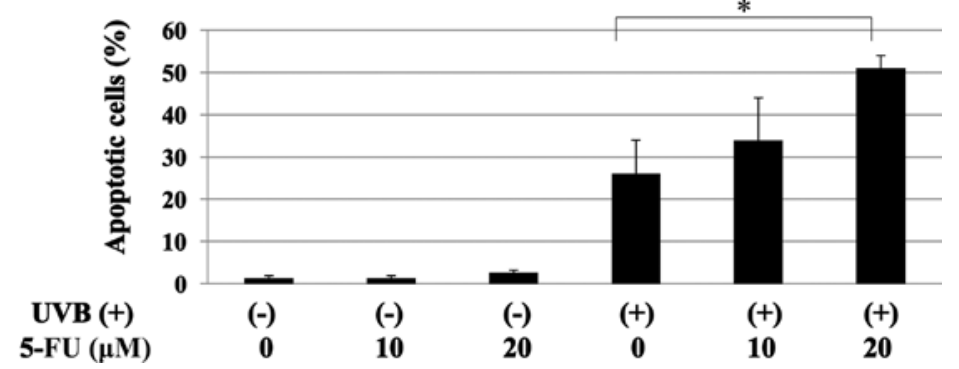

Figure 3. UVB-induced apoptosis of MCF-7 cells detected by fluorescence microscopy was potentiated by 5-fluorouracil (5-FU). (A) Representative image of MCF-7 cells treated in the absence or presence of 5-FU (10 or $20 \mu \mathrm{M})$ without or with UVB-irradiation $\left(750 \mathrm{~mJ} / \mathrm{cm}^{2}\right)$, stained by Hoechst 33258 . Cells exhibiting highly condensed and fragmented nuclear morphology were counted as apoptotic cells, and the percentage of apoptotic cells is documented in B. The rate of apoptotic cells was expressed as mean \pm SD of three individual experiments. The percentage of apoptotic cells was minimal upon treatment with 5-FU alone (1.3 vs. 1.3 and 2.3\%; untreated vs. treated with 5-FU at 10 and $20 \mu \mathrm{M}$ ). Treatment with UVB alone caused a slight increase in apoptotic cells (1.3 vs. $26.0 \%$; untreated vs. UVB alone), while a significant increase in apoptosis was noted upon combination treatment of 5-FU and UVB (26.0 vs. 34.3 and 50.6\%; UVB alone vs. UVB $+5-\mathrm{FU}$ at 10 and $20 \mu \mathrm{M}) .{ }^{*} \mathrm{P}<0.05$.

by the Annexin V/PI assay, UVB alone induced an increase in apoptotic cells to approximately 40 and to approximately $25 \%$ as indicated by the Hoechst 33258 staining assay. This difference was attributed to the detection ability of these methods; the Annexin V/PI assay is able to detect cells in the early phase of apoptosis, i.e., when membrane changes occur without nuclear fragmentation, whereas the Hoechst 33258 staining assay detects only cells with nuclear fragmentation and chromatin condensation. Moreover, analysis of the cell cycle revealed that treatment with UVB alone resulted in a significant increase in the percentage of cells in the G1 phase of the cell cycle.

In contrast, the inhibitory effect of 5-FU alone (10 and $20 \mu \mathrm{M}$ ) on cell viability, as evaluated by the trypan blue staining, was found to be 18 and $36 \%$, and this effect was also dependent partially on the induction of apoptosis but mostly on intra-S phase cell cycle arrest. The percentage of apoptotic cells increased by approximately 3 and 5\% following 5-FU treatment at 10 and $20 \mu \mathrm{M}$, respectively, as indicated by the Annexin V/PI assay, and approximately 1 and $2 \%$ as indicated by the Hoechst 33258 staining assay. Notably, a significant intra-S phase arrest was observed upon cell cycle analysis. The percentage of cells in the $\mathrm{S}$ phase increased by 19.3 and $15.4 \%$ after a $24-\mathrm{h}$ treatment with $5-\mathrm{FU}$ at 10 and $20 \mu \mathrm{M}$, respectively, and by 2.4 and $15.8 \%$, respectively, following a 48-h treatment. Therefore, the effect of 5-FU alone on MCF-7 cells was mostly dependent on intra-S phase cell cycle arrest, particularly at the time UVB-irradiation was performed. Following a 48-h treatment, intra-S arrest was observed only with treatment of 5-FU at $20 \mu \mathrm{M}$, which is probably dependent on the metabolic degradation of the drug in in vitro settings.

When UVB-irradiation was combined with 5-FU, a significant potentiation of the inhibitory effect on MCF-7 cells was observed. Cell viability decreased by 70 and $80 \%$, respectively, with 5-FU at 10 and $20 \mu \mathrm{M}$, and the percentage of apoptotic cells increased by 22 and 34\%, respectively, following Annexin V/PI staining, and by 8 and $26 \%$, respectively, following Hoechst 33258 staining assay. A significant increase in the percentage of intra-S cells was also observed. When compared to cells treated without 5-FU and without UVB-irradiation, there was a 12.8 and $12.4 \%$ increase in the percentage of cells in the intra-S phase, respectively, with 5-FU at 10 and $20 \mu \mathrm{M}$. Of note is that this increase was not accompanied by cell arrest in the G1 phase; however, a simultaneous was noted decrease in cells in the G2/M phase.

Previously, Hamaoka et al (27) reported that a combination treatment of 5-FU and UV-irradiation resulted in an additive inhibitory effect on the cell growth of MCF-7 cells and was hypothesized to be dependent on rRNA inhibition. Although the present findings are similar, we found that the effect was not merely additive, but that synergism occurred between 5-FU and UVB with regards to the inhibitory effect on cell viability. These data are strongly suggestive of the radiosensitization of human breast cancer cells by 5-FU. The difference between our findings and those of the previous report was possibly dependent on the time point UVB-irradiation was applied during 5-FU treatment. Our treatment protocol was 
UVB (-)

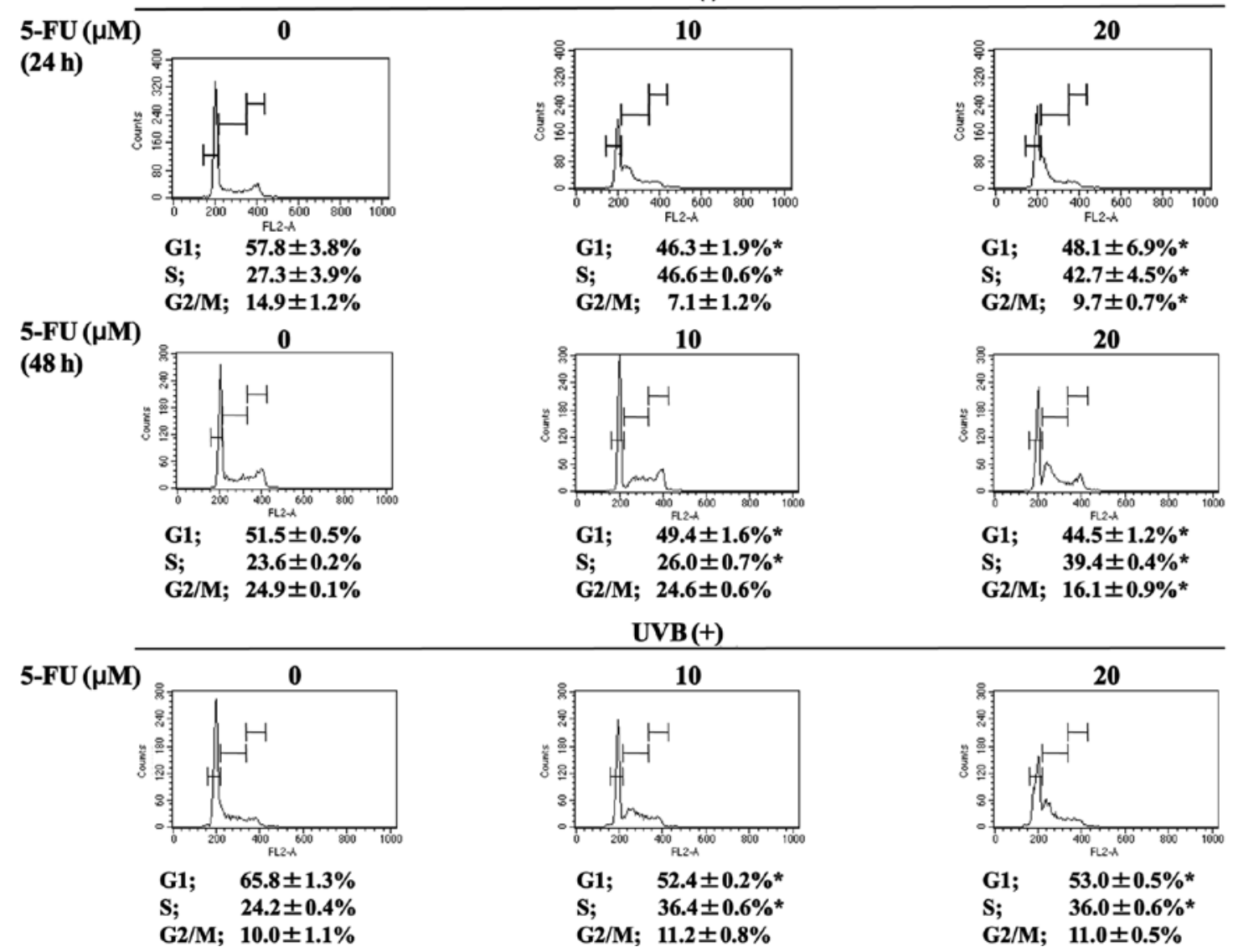

Figure 4. 5-Fluorouracil (5-FU) sensitized MCF-7 cells to UVB-irradiation by induction of intra-S phase cell cycle arrest. Changes in the cell cycle were quantified by flow cytometry after PI staining of MCF-7 cells, after treatment without or with 5-FU (10 or 20 $\mu$ M), and without or with UVB-irradiation $\left(750 \mathrm{~mJ} / \mathrm{cm}^{2}\right)$. Values are expressed as the mean \pm SD of 3 different experiments. Treatment of MCF-7 cells with 5 -FU alone for $24 \mathrm{~h}$ resulted in intra-S cell cycle arrest (percentage of cells in S phase: $27.3 \pm 3.9$ vs. $46.6 \pm 0.6$ and $42.7 \pm 4.5 \%$; untreated vs. 5 -FU at 10 and $20 \mu \mathrm{M}$ ), which became less evident after $48 \mathrm{~h}$ of treatment with 5 -FU alone (percentage of cells in S phase: $23.6 \pm 0.2$ vs. $26.0 \pm 0.7$ and $39.4 \pm 0.4 \%$; untreated vs. 5-FU at 10 and $20 \mu \mathrm{M}$ ). Compared with UVB treatment alone, the combination of 5-FU and UVB resulted in strong arrest of cells in the intra-S phase of the cell cycle $(24.2 \pm 0.4$ vs. $36.4 \pm 0.6$ and $36.0 \pm 0.6 \%$; UVB alone vs. UVB $+5-\mathrm{FU}$ at 10 and $20 \mu \mathrm{M}$ ). ${ }^{*} \mathrm{P}<0.05$ vs. control group (untreated or UVB alone).

based on the continuous treatment of cells with 5 -FU for $24 \mathrm{~h}$, after which UVB-irradiation was administered, and the cells were then treated for a further $24 \mathrm{~h}$ in the presence of 5-FU. When translating this protocol to the clinical setting, a patient should receive continuous administration of 5-FU, either orally or intravenously, and UVB-irradiation should be administered in the midterm. The optimal protocol remains to be confirmed in animal experiments before clinical trials are initiated.

The cytotoxic effect of 5-FU is caused by the inhibition of thymidylate synthase and incorporation into RNA and DNA (11). The exact mechanism by which 5-FU increases radiation sensitivity remains to be elucidated, but a number of mechanisms at the cellular level have been reported (28). One mechanism involves the killing of cells in the $\mathrm{S}$ phase of the cell cycle, which are relatively radioresistant compared to cells in the G2/M phase (29). McKay et al (30) reported that UV-induced apoptosis was greatly reduced by inhibiting S-phase progression, suggesting that the induction of apoptosis requires $\mathrm{S}$-phase progression following $\mathrm{UV}$-irradiation. Notably, as was the case in our previous report using human colon cancer cells (31), 5-FU treatment significantly increased intra-S cell cycle arrest in human breast cancer MCF-7 cells as well. The inappropriate progression through the $\mathrm{S}$ phase, such as disordered S-phase checkpoints, induced by drugs, is a possible mechanism of the enhancement of radiation sensitivity. A previous report (32) found that human colon cancer HT-29 cells, which express activated G1/S cyclins, but not SW620 cells, which do not show activated cyclins, are radiosensitized by fluorodeoxyuridine under identical drug treatment conditions. The blockade of S phase entry or inhibition of progression into the $\mathrm{S}$ phase has also been reported to inhibit sensitization $(33,34)$. Collectively, these reports and our findings suggest that the enhancement of the sensitization of MCF-7 breast cancer cells to UVB, induced by 5-FU is, at least partly, dependent on the induction of cell cycle arrest during the $\mathrm{S}$ phase.

Notably, in their study, Panno et al (35) showed that psoralen alone, or in combination with ultraviolet A (UVA, range 320-400 $\mathrm{nm}$ ) (PUVA) significantly affected the proliferation of breast cancer cells, including MCF-7. The inhibitory effect of PUVA was mostly dependent on induction of apoptosis, as detected by an increase in p53, caspase activation and DNA ladder. The use of ultraviolet irradiation at different ranges, with psoralen as the photosensitizer, corroborates our findings and potentially allows for the use of photochemotherapy in the clinical setting of breast cancer treatment. 
Since UVB phototherapy and 5-FU are already clinically available, and the doses of 5-FU and UVB-irradiation tested in the present study are relatively close to those physiologically achievable in human plasma and human skin, respectively, their use in clinical settings of anti-cancer therapy may be feasible $(5,36)$. In light of our results, the combination therapy of UVB phototherapy and 5-FU should be considered as a promising new candidate therapeutic modality for patients with locoregional recurrence of breast cancer, as well as other skin lesions infiltrated by malignant tumors, particularly those for whom the use of radiotherapy is limited by prior therapies.

In conclusion, we demonstrated that the combination therapy of UVB and 5-FU is an effective and promising strategy for the treatment of breast cancer, particularly for locoregional recurrence. 5-FU enhanced UVB-induced apoptosis in MCF-7 cells by the induction of cell cycle arrest during the $\mathrm{S}$ phase. Since UVB phototherapy and 5-FU are already in clinical use as anti-cancer agents, application of the combination treatment for breast cancer may be feasible without the need for phase I studies.

\section{Acknowledgements}

The authors thank Ms. Mika Matsuhashi, Ms. Michiru Kawabata and Mr. Naoyuki Yoshikawa of the Department of Transfusion Medicine (University of Tokyo) for their kind advisory and technical assistance.

\section{References}

1. Lui H: Phototherapy of psoriasis: update with practical pearls. J Cutan Med Surg 6: 17-21, 2002.

2. Reynolds NJ, Franklin V, Gray JC, Diffey BL and Farr PM: Narrow-band ultraviolet B and broad-band ultraviolet A phototherapy in adult atopic eczema: a randomised controlled trial. Lancet 357: 2012-2016, 2001.

3. Hamzavi I, Jain H, McLean D, Shapiro J, Zeng H and Lui H: Parametric modeling of narrowband UV-B phototherapy for vitiligo using a novel quantitative tool: the Vitiligo Area Scoring Index. Arch Dermatol 140: 677-683, 2004.

4. Gathers RC, Scherschun L, Malick F, Fivenson DP and Lim HW: Narrowband UVB phototherapy for early-stage mycosis fungoides. J Am Acad Dermatol 47: 191-197, 2002.

5. Matsuoka Y, Yoneda K, Katsuura J, et al: Successful treatment of follicular cutaneous T-cell lymphoma without mucinosis with narrow-band UVB-irradiation. J Eur Acad Dermatol Venereol 21: 1121-1122, 2007.

6. Snellman E, Klimenko T and Rantanen T: Randomized half-side comparison of narrowband UVB and trimethylpsoralen bath plus UVA treatments for psoriasis. Acta Derm Venereol 84: 132-137, 2004.

7. Halliday GM: Inflammation, gene mutation and photoimmunosuppression in response to UVR-induced oxidative damage contributes to photocarcinogenesis. Mutat Res 571: 107-120, 2005.

8. Griffiths HR, Mistry P, Herbert KE and Lunec J: Molecular and cellular effects of ultraviolet light-induced genotoxicity. Crit Rev Clin Lab Sci 35: 189-237, 1998.

9. Cotton J and Spandau DF: Ultraviolet B-radiation dose influences the induction of apoptosis and p53 in human keratinocytes. Radiat Res 147: 148-155, 1997.

10. Aufiero BM, Talwar H, Young C, et al: Narrow-band UVB induces apoptosis in human keratinocytes. J Photochem Photobiol B 82: 132-139, 2006.

11. Longley DB, Harkin DP and Johnston PG: 5-Fluorouracil: mechanisms of action and clinical strategies. Nat Rev Cancer 3: 330-338, 2003

12. Huerta S, Gao X, Livingston EH, Kapur P, Sun H and Anthony T: In vitro and in vivo radiosensitization of colorectal cancer HT-29 cells by the smac mimetic JP-1201. Surgery 148: 346-353, 2010.
13. Dai Y, Liu M, Tang W, et al: Molecularly targeted radiosensitization of human prostate cancer by modulating inhibitor of apoptosis. Clin Cancer Res 14: 7701-7710, 2008.

14. Adamsen BL, Kravik L and De Angelis PM: Cellular response to chemoradiotherapy, radiotherapy and chemotherapy in two colorectal cancer cell lines. Radiat Res 171: 562-571, 2009.

15. Wilson GD, Bentzen SM and Harari PM: Biologic basis for combining drugs with radiation. Semin Radiat Oncol 16: 2-9, 2006.

16. Clarke M, Collins R, Darby S, et al: Effects of radiotherapy and of differences in the extent of surgery for early breast cancer on local recurrence and 15-year survival: an overview of the randomised trials. Lancet 366: 2087-2106, 2005.

17. Shikama N, Sekiguchi K and Nakamura N: Management of locoregional recurrence of breast cancer. Breast Cancer: May 7, 2010 (Epub ahead of print).

18. Taylor ME: Breast cancer: chest wall recurrences. Curr Treat Options Oncol 3: 175-177, 2002.

19. Holme SA and Mills CM: Crotamiton and narrow-band UVB phototherapy: novel approaches to alleviate pruritus of breast carcinoma skin infiltration. J Pain Symptom Manage 22: 803-805, 2001.

20. Nakayama S, Katoh EM, Tsuzuki T and Kobayashi S: Protective effect of alpha-tocopherol-6-O-phosphate against ultraviolet $\mathrm{B}$-induced damage in cultured mouse skin. J Invest Dermatol 121: 406-411, 2003.

21. Cai BX, Luo D, Lin XF and Gao J: Compound K suppresses ultraviolet radiation-induced apoptosis by inducing DNA repair in human keratinocytes. Arch Pharm Res 31: 1483-1488, 2008.

22. Fergin P: Photodynamic therapy of dermatoses other than nonmelanoma skin cancer. Australas J Dermatol 46 (Suppl 3): S27, 2005.

23. Babilas P, Karrer S, Sidoroff A, Landthaler M and Szeimies RM: Photodynamic therapy in dermatology - an update. Photodermatol Photoimmunol Photomed 21: 142-149, 2005.

24. Saad ED and Hoff PM: UFT and oral leucovorin as radiation sensitizers in rectal and other gastrointestinal malignancies. Cancer Invest 21: 624-629, 2003.

25. Zenda S, Onozawa Y, Tahara M, et al: Feasibility study of single agent cisplatin and concurrent radiotherapy in Japanese patients with squamous cell carcinoma of the head and neck: preliminary results. Jpn J Clin Oncol 37: 725-729, 2007.

26. Choy H, Rodriguez FF, Koester S, Hilsenbeck S and von Hoff DD: Investigation of taxol as a potential radiation sensitizer. Cancer 71: 3774-3778, 1993.

27. Hamaoka T, Furuya Y, Yamamoto K and Kuroda Y: MCF-7 growth inhibition by ultraviolet radiation and 5-fluorouracil: the importance of treatment sequence. Cancer Lett 154: 183-187, 2000.

28. Lawrence TS, Blackstock AW and McGinn C: The mechanism of action of radiosensitization of conventional chemotherapeutic agents. Semin Radiat Oncol 13: 13-21, 2003.

29. Byfield J: Useful interactions between 5-fluorouracil and radiation in man: 5-fluorouracil as a radiosensitizer. CRC Press, Boca Raton, FL, 1990.

30. McKay BC, Becerril C, Spronck JC and Ljungman M: Ultraviolet light-induced apoptosis is associated with S-phase in primary human fibroblasts. DNA Repair (Amst) 1: 811-820, 2002.

31. Sasaki K, Tsuno NH, Sunami E, et al: Chloroquine potentiates the anti-cancer effect of 5-fluorouracil on colon cancer cells. BMC Cancer 10: 370, 2010.

32. Lawrence TS, Davis MA and Loney TL: Fluoropyrimidinemediated radiosensitization depends on cyclin E-dependent kinase activation. Cancer Res 56: 3203-3206, 1996.

33. Naida JD, Davis MA and Lawrence TS: The effect of activation of wild-type p53 function on fluoropyrimidine-mediated radiosensitization. Int J Radiat Oncol Biol Phys 41: 675-680, 1998.

34. Lawrence TS, Davis MA, Tang HY and Maybaum J: Fluorodeoxyuridine-mediated cytotoxicity and radiosensitization require S phase progression. Int J Radiat Biol 70: 273-280, 1996.

35. Panno ML, Giordano F, Mastroianni F, et al: Breast cancer cell survival signal is affected by bergapten combined with an ultraviolet irradiation. FEBS Lett 584: 2321-2326, 2010.

36. Fraile RJ, Baker LH, Buroker TR, Horwitz J and Vaitkevicius VK: Pharmacokinetics of 5-fluorouracil administered orally, by rapid intravenous and by slow infusion. Cancer Res 40: 2223-2228, 1980. 